\title{
Indications and outcomes of emergency obstetric hysterectomy; a 5-year review at the Bafoussam Regional Hospital, Cameroon
}

Mbakwa Rickeins Mbakwa ${ }^{1,2^{*}}$, Nicholas Tendongfor ${ }^{1}$, Yannick Lechedem Ngunyi ${ }^{1,3}$, Ekongefeyin Sintieh Nchinda Ngek ${ }^{1,4}$, Frank Alemkia ${ }^{1}$ and Thomas Obinchemti Egbe ${ }^{1,5}$

\begin{abstract}
Background: Emergency Obstetric Hysterectomy $(\mathrm{EOH})$ is removal of the uterus due to life threatening conditions within the puerperium. This life saving intervention is associated with life threatening complications. In our setting, little is known on $\mathrm{EOH}$.

Objectives: To determine the prevalence, indications and outcomes of emergency obstetric hysterectomy while comparing both postpartum hysterectomy and caesarean hysterectomy.

Methods: A 5-year hospital-based retrospective cohort study involving medical records of patients who underwent emergency obstetric hysterectomies between 1st January 2015 and 31st December 2019, was carried out at the Bafoussam Regional Hospital (BRH) from 1st February 2020 to 30th April 2020. Cases were classified as caesarean hysterectomy $(\mathrm{CH})$ or postpartum hysterectomy $(\mathrm{PH})$. Epidemiological data, indications, and complications of EOH were collected and analyzed in EPI-INFO 7.2.2.1. The chi-squared test was used to compare the two groups, and bivariate analysis was used to identify indicators of adverse outcomes of EOH. Statistical significance was set at $p<$ 0.05
\end{abstract}

Results: There were 30 cases of emergency obstetric hysterectomy (24 caesarean hysterectomies and 6 postpartum hysterectomies), giving a prevalence rate of 3.75 per 1000 deliveries. The most common indication for $\mathrm{CH}$, was intractable postpartum haemorrhage and uterine rupture (33.33\% each), while abnormal placentation (50\%) was commonly indicated for PH. Anaemia (both groups) $(p=0.013)$ and sepsis (PH group only, 33.33\%) $(p=0.03)$ were the most statistically significant complications of $\mathrm{EOH}$ respectively. Absence of blood transfusion prior to surgery $(p=0.013)$ and prolonged surgery lasting 2 or more hours $(p=0.04)$, were significantly associated with a negative clinical outcome.

\footnotetext{
* Correspondence: mbakwa@rocketmail.com

${ }^{1}$ Faculty of Health Sciences, University of Buea, Buea, Cameroon

${ }^{2}$ Microhealth Global Medical Center, Mbengwi, Cameroon

Full list of author information is available at the end of the article
}

(C) The Author(s). 2021 Open Access This article is licensed under a Creative Commons Attribution 4.0 International License, which permits use, sharing, adaptation, distribution and reproduction in any medium or format, as long as you give appropriate credit to the original author(s) and the source, provide a link to the Creative Commons licence, and indicate if changes were made. The images or other third party material in this article are included in the article's Creative Commons licence, unless indicated otherwise in a credit line to the material. If material is not included in the article's Creative Commons licence and your intended use is not permitted by statutory regulation or exceeds the permitted use, you will need to obtain permission directly from the copyright holder. To view a copy of this licence, visit http://creativecommons.org/licenses/by/4.0/. The Creative Commons Public Domain Dedication waiver (http://creativecommons.org/publicdomain/zero/1.0/) applies to the data made available in this article, unless otherwise stated in a credit line to the data. 


\begin{abstract}
(Continued from previous page)
Conclusion: The prevalence of EOH is high. There were no differences in the sociodemographic profile, risk factors and indications of both groups. PH group was more likely to develop sepsis as complication. Lack of blood transfusion prior to surgery and prolonged surgeries were significantly associated to complication. Meticulous care and timely recognition of negative prognostic factors of delivery as well as those of $\mathrm{EOH}$ will help improve maternal outcomes of pregnancy.
\end{abstract}

Keywords: Emergency obstetric hysterectomy, Caesarean hysterectomy, Postpartum hysterectomy, Complications, Indications, Predictors of adverse outcomes, Bafoussam Regional Hospital, Cameroon

\section{Background}

EOH could be due to clinical indications such as lifethreatening haemorrhage not responding to medical treatment, uterine rupture, abnormal placentation (placenta accreta) and sepsis. Emergency obstetric hysterectomy $(\mathrm{EOH})$ is defined as the removal of the uterus either at the time of caesarean section (CS) or following vaginal delivery (VD) within the puerperium and it is usually performed in the face of life-threatening obstetric haemorrhage [1]. EOH is characterized with the dilemma of choosing between saving a life and sacrificing fertility, hence it is of importance this is prevented as much as possible. In Cameroon, despite the maternal mortality ratio (MMR) falling gradually from 749 deaths per 100,000 live births in 1998 to 467 deaths per 100,000 live births in 2018 [2] postpartum haemorrhage (PPH), a key indicator of $\mathrm{EOH}$ accounted for $29.2 \%$ of all maternal mortality [3]. Even though rendering the woman sterile, emergency obstetric hysterectomy is the bridge between life threatening postpartum haemorrhage and death. Emergency obstetric hysterectomy complicates almost 1 per 1000 deliveries world-wide ranging from $0.2-10.1$ per 1000 births, with the prevalence higher in low and middle income, than upper middle and high income settings: 2.8 compared with 0.7 per 1000 deliveries respectively [4]. In Nigeria and Cameroon, the incidence of $\mathrm{EOH}$ are 5.1 and 1.25 per 1000 deliveries respectively with the incidence of Caesarean hysterectomies $(\mathrm{CH})$ higher than postpartum hysterectomies (PH) in both settings $[5,6]$. In Greece, placenta accreta accounted for $51.1 \%$ of $\mathrm{EOH}$ as compared to uterine rupture which accounted for 93.2 and 35\% in Nigeria and Cameroon respectively [5-7]. Proper timing and meticulous care may reduce or prevent maternal complications. Despite the lifesaving intervention of the $\mathrm{EOH}$, these patients must be monitored closely to prevent further complications such as wound infection, renal failure, disseminated intravascular coagulation (DIC), shock, septicemia and mortality [8]. Given that the incidence of this procedure is on the rise as a consequence to the rise in irreversible causes of life threatening haemorrhage, abnormal placentation and uterine rupture $[9,10]$, it requires utmost attention, as this will play a vital role to curb maternal mortality. With paucity of data on emergency obstetric hysterectomy in our setting, gradual drop in maternal mortality rate and the universal rising trend in Caesarean delivery as reported by WHO $(12 \%$ in 2000 to $21 \%$ in 2015) [11], the importance of understanding the overall healthcare burden of $\mathrm{EOH}$ cannot be over-emphasized. Given our hypothesis that the prevalence of $\mathrm{EOH}$ is high, we therefore sort to assess the current trend of $\mathrm{EOH}$ in Cameroon and shed light on the prevalence, as well as comparing both postpartum hysterectomy and caesarean hysterectomy and its outcomes. This will help provide base line data, that could be useful for the formulation of better treatment guidelines, hence reducing maternal mortality in our setting.

\section{Methods}

\section{Study design and setting}

This was a hospital-based retrospective cohort study, conducted between 1st February 2020 to 30th April 2020 at the inpatient department of obstetrics and gynaecology of the Bafoussam regional hospital (BRH). The Bafoussam Regional Hospital (BRH), is located in the Bafoussam II subdivision, in the Mifi Division of the West Region of Cameroon. The BRH is a secondary healthcare facility that offers medical education, clinical care, and research to a population of over 1.5 million inhabitants of the city of Bafoussam and its environs. The Obstetrics and Gynaecology department has 3 obstetricians, 16 paramedical staff (comprising of midwives, nurses and assistant nurses), 3 outpatient consultation rooms, 1 delivery room, 5 delivery beds and 30 hospitalization beds with an annual average of 1500 deliveries.

\section{Study population and sampling}

We included medical records of all pregnant women who gave birth at the BRH from 28 completed weeks of gestation to term and underwent hysterectomy in the puerperium because of a complication during birth, from 1st January 2015 to 31st December 2020. 


\section{Data collection}

Data were collected from admission registers of the department of obstetrics and gynaecology at the BRH, theatre registers and files from surgical wards, using a predesigned data collection form. Collected data included, socio-demographic characteristics (age, antenatal visits, referral status), obstetric history (parity, previous uterine scar, curettage), type of delivery (vaginal or caesarean), clinical indicators (uterine rupture, intractable postpartum hemorrhage, uterine atony) and possible outcomes (sepsis, DIC, wound infection, acute kidney injury) of emergency obstetric hysterectomies.

\section{Statistical analysis}

The collected data was entered into and analysed with EPI-INFO 7.2.2.1.

\section{Dependent variable}

Indications (intractable postpartum hysterectomy, uterine atony, abnormal placentation and uterine rupture) and outcomes (sepsis, anaemia, acute kidney injury and wound infection) of $\mathrm{EOH}$ were outlined and the frequency and percentages at which they occurred were calculated.

\section{Independent variables}

Age, number of antenatal visits, referral status, type of surgery, parity.

Predictors of adverse outcomes were identified using bivariate analysis, and the predictor variables were grouped into sociodemographic or obstetric. Chisquared test was used to establish association between variables and to compare the two groups $(\mathrm{CH}$ and $\mathrm{PH})$. A $P$-value $<0.05$ was considered statistically significant.

\section{Ethics considerations}

The ethical clearance for this study was issued by the institutional Review Board of the Faculty of Health Sciences, University of Buea (ref. $N^{\text {o: }}$ 2019/1061-01/UB/ SG/IRB/FHS). An administrative approval was obtained from the Directorate of the Bafoussam Regional Hospital, Cameroon (ref. $\mathrm{N}^{\mathrm{o}}$ 297/L/MINSANTE/SSG/ DRSPO/HRB/D). To ensure confidentiality, all patient information was coded.

\section{Results}

A total of 7992 medical records were reviewed and there were 6364 vaginal and 1634 caesarean deliveries. Of these, 32 medical records were obstetric hysterectomies. Two cases of elective hysterectomies because of symptomatic uterine fibroids and cervical cancer in pregnancy were excluded from the study. There was no exclusion of cases on the basis of incomplete or missing data, giving a retrieval rate of $100 \%$. Therefore, 30 medical records of emergency obstetric hysterectomy (EOH) were included in the study; 24 caesarean hysterectomies $(\mathrm{CH})$ and 6 postpartum hysterectomies $(\mathrm{PH})$ (Table 1). Of the 30 cases, $10 \%$ (3/30) were referred from other hospitals for better management (Table 1).

\section{Characteristics of the study population}

The median age was 31.5 years (IQR: $27-36$ years). Thirteen $(43.33 \%)$ of cases were less than 30 years old. The median parity was 4 (IQR:2-5). Grand multiparity (5 or more births) accounted for 30\% (9/30) of cases while multiparity (2 to 4 births) and primiparity accounted for $53.33 \%(16 / 30)$ and $16.67 \%(5 / 30)$ respectively. Out of 30 cases, 93.3\% (28/30) attended ANC at least four times as against $6.7 \%(2 / 30)$ who did attend ANC less than four times (Table 2).

\section{Prevalence of emergency obstetric hysterectomy,} postpartum hysterectomy and caesarean hysterectomy The prevalence of emergency obstetric hysterectomy was 3.75 per 1000 livebirths (30/7992). Twenty-four cases underwent hysterectomy after caesarean deliveries 24/7992 (prevalence of 3.0/1000 livebirths) and six after vaginal deliveries 6/7992 (prevalence of $0.75 / 1000$ livebirths).

\section{Characteristics of emergency obstetric hysterectomy}

Multiparity occurred in 25 (83.33\%) cases. Multiparity (25), uterine atony (10), were more likely to lead to caesarean hysterectomy $(\mathrm{CH})$ than postpartum hysterectomy $(\mathrm{PH})$ (Table 3$)$.

\section{Indications of emergency obstetric hysterectomies}

Intractable postpartum haemorrhage 10 (33.33) was the most frequent indication of $\mathrm{EOH}$, with the same odds of being an indication for both postpartum hysterectomy and caesarean hysterectomy (Table 4).

\section{Complications of emergency obstetric hysterectomy}

The most frequent complication of $\mathrm{EOH}$ was anaemia (27, 90\%). Other than sepsis which had a significant difference in both caesarean hysterectomies and postpartum hysterectomies, there were no statistically significant differences for anaemia, AKI and wound infections. There was an overall 1 (3.85\%) mortality, 1 (3.85\%) for $\mathrm{CH}$ and 0 (00\%) for $\mathrm{PH}$, but there was no statistically significant difference in mortality rate between $\mathrm{CH}$ and $\mathrm{PH}$ (Table 5).

\section{Predictors of adverse clinical outcomes of emergency obstetric hysterectomy}

Age, parity, referral status, transfusion prior to surgery, type of surgery and method of delivery were evaluated as predictors of adverse clinical outcomes. In bivariate 
Table 1 Types of emergency obstetric hysterectomy (EOH)

\begin{tabular}{lllll}
\hline Type of EOH & Cases (\%) & Referred Cases (\%) & deliveries & Prevalence Per 1000 \\
\hline Caesarean hysterectomy & $24(80)$ & $2(6.67)$ & 1628 & 14.7 \\
Postpartum hysterectomy & $6(20)$ & $1(1.33)$ & 6364 & 0.9 \\
Total & $30(100)$ & $3(10)$ & 7992 & 3.75 \\
\hline
\end{tabular}

EOH Emergency obstetric hysterectomy

analysis, participants who did not receive blood transfusion prior to surgery were 25 -fold more likely to be anaemic after EOH (OR 25; 95\%CI: $1.52-410.89 ; p=0.04$ ) (Table 6).

\section{Discussion}

We observed an overall high prevalence rate of $\mathrm{EOH}$ ( 1 in about 267 deliveries). This is higher than the 1.25 per 1000 deliveries and the 1.14 per 1000 deliveries reported in two tertiary hospitals in Yaounde and Douala, Cameroon [6, 12]. This difference could be due to the fact that both Douala and Yaounde teaching hospitals are tertiary hospitals and more equipped to monitor and handle deliveries hence preventing complications which could require $\mathrm{EOH}$ as last resort. Furthermore, the Douala and Yaounde teaching hospitals have more experienced medical personnel to better perform deliveries. Our prevalence of 1 in 267 deliveries is however within the global range [13] and similar to the 5.1 per 1000 deliveries reported by Nwobodo et al. [5] at a tertiary hospital in Sokoto, Nigeria. The prevalence was higher than the 1 in 1429 deliveries reported in upper middle and high income countries [4]. This could be due to better obstetric care in such settings. Among the 30 cases of $\mathrm{EOH}$, more than 3 in 4 were caesarean hysterectomy which was similar to

Table 2 Sociodemographic characteristics of $\mathrm{EOH}$

\begin{tabular}{lll}
\hline Variable & Frequency & Percentage (\%) \\
\hline Maternal age (years) & & \\
$<20$ & 2 & 6.7 \\
$20-30$ & 13 & 43.3 \\
$>30$ & 15 & 50.0 \\
Parity & & \\
Primipara & 5 & 16.7 \\
$2-4$ & 16 & 53.3 \\
$\geq 5$ & 9 & 30.0 \\
ANC visits & & \\
$\geq 4$ & 28 & 93.3 \\
$<4$ & 2 & 6.7 \\
\hline
\end{tabular}

ANC antenatal care reports (70) by Forna et al. [14]. Multiparity (83.33\%) was the most frequent risk factor in our study. This was similar to findings from a system review by Rossi et al in 2010 [15]. Also, reports by Njamen et al in 2017, indicated that, every 3 in 4 cases of $\mathrm{EOH}$, involved a multiparous woman [12]. Multiparous patients were more than 3 times more like to have a $\mathrm{CH}$ than $\mathrm{PH}$. There was no statistically significant difference, drawing similarity with a study done by Lee and To in Hong Kong [16]. Intractable postpartum haemorrhage (33.3\%) followed by Uterine atony (30\%) were the most common indication of $\mathrm{EOH}$, this finding ties with that in studies by Forna et al. [14] in the US and Njamen et al. [12] in Cameroon. Comparison of indications of emergency obstetric hysterectomy revealed that the primary cause of $\mathrm{CH}$ was intractable postpartum haemorrhage $(33.33 \%)$ and uterine rupture $(33.33 \%)$ and in the $\mathrm{PH}$ group, abnormal placentation (50\%) was the primary indication, similarly, to Forna et al. [14], but there were no significant differences in the indications of $\mathrm{CH}$ and $\mathrm{PH}$. Approximately 9 in every 10 patients had a complication following emergency obstetric hysterectomy. The most frequent complication of $\mathrm{EOH}$ was anaemia which occurred 9 times in every 10 patients. This could be due to the delay in acquiring blood as in our setting, the blood banks are frequently dried out, and getting a donor is daunting task, ranging from identification to pretransfusion laboratory workups which take a lot of time. Emergency obstetric hysterectomy patients who delivered vaginally had a statistically higher chance of developing sepsis when compared to those who underwent $\mathrm{EOH}$ following caesarean section. This could be attributed to the fact that the delivery rooms in our settings are relatively more septic than the theatres as there is little knowledge and application of basic hygiene measures in our labour rooms by nurses as compared to doctors in the theatre. Furthermore, vaginal deliveries entail a longer duration and require multiple vaginal examinations which is significantly associated with intraamniotic infections which could lead to sepsis $[17,18]$. Preoperative antibiotics prophylaxis is significantly associated with reduced wound infection which is a 
Table 3 Characteristic of emergency obstetric hysterectomy cases ( $\mathrm{CH}$ vs $\mathrm{PH}$ )

\begin{tabular}{llll}
\hline Risk factors & Frequency of EOH (\%) & CH & N (\%) \\
Multiparity & & $21(87.50)$ & N (\%) \\
\hline Uterine atony & $25(83.33)$ & $9(37.50)$ & $4(66.67)$ \\
Previous uterine scar & $10(33.33)$ & $8(33.33)$ & $1(16.67)$ \\
Previous uterine curettage & $8(26.67)$ & $5(12.50)$ & $0(00)$ \\
Placenta accreta & $5(16.67)$ & $3(12.50)$ & $3(33.33)$ \\
Coagulopathy & $4(13.33)$ & $3(12.50)$ & $0(00)$ \\
Uterine rupture & $3(10.00)$ & $2(8.33)$ & $0(00)$ \\
\hline
\end{tabular}

$\mathrm{CH}$ caesarean hysterectomy, $\mathrm{PH}$ postpartum hysterectomy, $\mathrm{EOH}$ emergency obstetric hysterectomy

cause of sepsis [19-21], but in our setting, there is usually no administration of prophylactic antibiotic therapy during vaginal delivery as recommended in caesarean section. Again, EOH following vaginal delivery is usually followed by multiple desperate emergency maneuvers like uterine curettage, uterine packing and insertion of utero-tonics in attempt to save the woman's life which increases the chances of sepsis. Recognition of pre-operative predictors of adverse outcomes such as: age, parity, referral status, duration of surgery, type of surgery, duration from indication to surgery, blood transfusion, method of delivery were assessed. Patients who weren't transfused prior to surgery had a significant chance of having an adverse outcome. Patients who were not transfused were 25 times more likely to have anaemia after surgery. Also, patients whose surgery lasted $2 \mathrm{~h}$ and more were significantly more likely to develop an adverse outcome. A possible reason for this, could be prolonged bleeding, hence anaemia. In our study, 9 in every 10 patients had anaemia. Extensive probe of existing literature for comparative analysis, to the best of our knowledge proved abortive, with respect to finding studies that assessed predictors of adverse outcomes of EOH.

\section{Strengths of the study}

To the best of our knowledge, this is one of the few studies in Africa that compares and brings out the difference and similarities in the clinical profile, indications

Table 4 Indications of $\mathrm{EOH}$

\begin{tabular}{llll}
\hline Indications & Frequency of EOH (\%) & $\begin{array}{l}\text { CH } \\
\text { N (\%) }\end{array}$ & $\begin{array}{l}\text { PH } \\
\text { N (\%) }\end{array}$ \\
\hline Intractable PPH & $10(33.33)$ & $8(33.3)$ & $2(33.3)$ \\
Uterine Atony & $9(30)$ & $7(29.17)$ & $2(33.33)$ \\
Abnormal Placentation & $8(26.67)$ & $5(20.83)$ & $3(50)$ \\
Uterine rupture & $8(26.67)$ & $8(33.3)$ & $0(00)$ \\
\hline
\end{tabular}

$\mathrm{CH}$ caesarean hysterectomy, $\mathrm{PH}$ postpartum hysterectomy, $\mathrm{EOH}$ emergency obstetric hysterectomy, $\mathrm{PPH}$ postpartum haemorrhage and outcomes of caesarean hysterectomy $(\mathrm{CH})$ and postpartum hysterectomy (PH). Additionally, our study contributes to the data on the prevalence, indications and outcomes of emergency obstetric hysterectomies in Cameroon and the world at large. Furthermore, our study provides new data on clinical outcomes and the predictors of these outcomes.

\section{Limitations of the study}

The sample size for this study was small thereby warranting studies with larger sample sizes. Furthermore, due to the retrospective design of the study, there was a possibility of getting inadequate or missing data in the medical records of some patients.

\section{Conclusion}

About 1 in 267 women who gave birth at the Bafoussam regional hospital underwent an emergency obstetric hysterectomy. Multiparity, intractable postpartum haemorrhage, and anaemia were the significant risk factor, indication and complication, respectively. Sepsis was significantly different between caesarean hysterectomy and postpartum hysterectomy. Cases that did not receive blood transfusion prior to surgery were more likely to present with anaemia. Despite being a life-saving endeavour, rendering a young woman sterile could have profound psycho-social effects. Efforts towards preventing

Table 5 Complications of EOH

\begin{tabular}{llll}
\hline Complications of EOH & Frequency of EOH (\%) & $\begin{array}{l}\text { CH } \\
\text { N (\%) }\end{array}$ & $\begin{array}{l}\text { PH } \\
\text { N (\%) }\end{array}$ \\
\hline Anaemia & $27(90)$ & $21(87.50)$ & $6(100)$ \\
Sepsis & $2(6.67)$ & $0(00)$ & $2(33.3)$ \\
AKI & $1(3.33)$ & $1(4.17)$ & $0(00)$ \\
Wound infection & $2(6.67)$ & $2(8.33)$ & $0(00)$ \\
Death & $1(3.33)$ & $1(3.33)$ & $0(00)$ \\
\hline $\begin{array}{l}\text { EOH emergency obstetric hysterectomy, AKI Acute kidney injury, PH } \\
\text { Postpartum hysterectomy, CH Caesarean hysterectomy }\end{array}$
\end{tabular}


Table 6 Predictors of adverse clinical outcome

\begin{tabular}{|c|c|c|c|c|c|c|}
\hline Variables & $\begin{array}{l}\text { Total } \mathrm{n}(\%) \\
N=30\end{array}$ & $\begin{array}{l}\text { Adverse outcome } \\
\mathrm{n}(\%) \\
n=28\end{array}$ & $\begin{array}{l}\text { No adverse outcome } \\
\mathrm{n}(\%) \\
n=2\end{array}$ & Risk ratio & Confidence interval & $p$-value \\
\hline \multicolumn{7}{|c|}{ Age (years) } \\
\hline$<30$ & $13(100)$ & $11(84.62)$ & $2(15.38)$ & 1.18 & $0.94-1.49$ & 0.18 \\
\hline$\geq 30$ & $17(100)$ & $17(100)$ & $0(00)$ & & & \\
\hline \multicolumn{7}{|c|}{ Multiparity } \\
\hline Yes & $25(100)$ & $24(96)$ & $1(4.00)$ & 1.2 & $0.77-1.87$ & 0.31 \\
\hline No & $5(100)$ & $4(80)$ & $1(20.00)$ & & & \\
\hline \multicolumn{7}{|l|}{ ANC } \\
\hline Yes & $27(100)$ & $25(92.59)$ & $2(7.41)$ & 0.9 & $0.83-1.03$ & 1.00 \\
\hline No & $2(100)$ & $2(100)$ & $0(00)$ & & & \\
\hline \multicolumn{7}{|l|}{ Referred } \\
\hline Yes & $3(100)$ & $3(100)$ & $0(00)$ & 1.1 & $0.97-1.2$ & 1.00 \\
\hline No & $27(100)$ & $25(92.59)$ & $2(7.41)$ & & & \\
\hline \multicolumn{7}{|c|}{ Blood transfusion } \\
\hline Yes & $4(100)$ & $2(50)$ & $2(50)$ & 0.5 & $0.19-1.33$ & $0.013^{*}$ \\
\hline No & $26(100)$ & $26(100)$ & $0(00)$ & & & \\
\hline \multicolumn{7}{|c|}{ Type of surgery } \\
\hline Subtotal & $27(100)$ & $25(92.59)$ & $2(7.41)$ & 0.9 & $0.83-1.03$ & 1.00 \\
\hline Total & $1(100)$ & $1(100)$ & $0(00)$ & & & \\
\hline \multicolumn{7}{|c|}{ Method of delivery } \\
\hline $\mathrm{C} / \mathrm{S}$ & $24(100)$ & $22(91.67)$ & $2(8.33)$ & 0.9 & $0.81-1.03$ & 1.00 \\
\hline VD & $6(100)$ & $6(100)$ & $0(00)$ & & & \\
\hline \multicolumn{7}{|c|}{ Duration of surgery (hours) } \\
\hline$<2$ & $6(100)$ & $4(66.67)$ & $2(33.33)$ & 0.67 & $0.38-1.17$ & $0.04^{*}$ \\
\hline$\geq 2$ & $22(100)$ & $22(100)$ & $0(00)$ & & & \\
\hline
\end{tabular}

ANC antenatal care, CS Caesarean section, VD vaginal delivery

* Statistically significant values

identified risk factors and indications thus becomes vital in order to curb high rates of $\mathrm{EOH}$ and sterility which induces a high psycho-social burden on our young women.

\section{Abbreviations}

ARDS: Acute respiratory distress syndrome; ANC: Antenatal clinic; BRH: Bafoussam Regional Hospital; CS: Caesarean section; CH: Caesarean hysterectomy; DIC: Disseminated intravascular coagulation; EOH: Emergency obstetric hysterectomy; EPH: Emergency peripartum hysterectomy; ICU: Intensive care unit; IQR: Interquartile range; PH: Postpartum hysterectomy; PPH: Post-partum haemorrhage; VD: Vaginal delivery; WHO: World Health Organization

\section{Acknowledgements}

We sincerely acknowledge the Management of the Bafoussam Regional Hospital, Cameroon, for granting us the permission to carry out this study in their institution.

\section{Authors' contributions}

MRM wrote the research protocol and designed the study: TOE, NT and ESNN corrected the protocol. MRM \& YLN collected the data and wrote the initial manuscript. MRM, TOE, NT, FA and ESNN proof-read and corrected the final manuscript. All authors approved the final manuscript.
Funding

None.

Availability of data and materials

The data sets supporting the findings of this study are available, and can be provided by the corresponding author on reasonable request.

\section{Declarations}

Ethics approval and consent to participate

Ethical clearance was obtained from the Institutional Review Board of the Faculty of Health Sciences, University of Buea (ref. N 2019/1061-01/UB/SG/ IRB/FHS), and administrative authorization was granted by the Directorate of the BRH, Cameroon (ref. N ${ }^{\circ}$ 297/L/MINSANTE/SSG/DRSPO/HRB/D). The need for informed consent was officially waived by the ethics committee of the Institutional Review Board of the Faculty of Health Sciences due to the retrospective design of the study and anonymous nature of the data collection process. All methods were performed in accordance with ethical guidelines as stipulated in the Declaration of Helsinki.

Consent for publication

Not applicable.

Competing interests

The authors declare that they have no competing interests. 


\section{Author details}

Faculty of Health Sciences, University of Buea, Buea, Cameroon.

${ }^{2}$ Microhealth Global Medical Center, Mbengwi, Cameroon. ${ }^{3}$ Mbonge District Hospital, Mbonge, Cameroon. ${ }^{4}$ Cameroon Baptist Convention Health Services, Yaounde, Cameroon. ${ }^{5}$ Obstetrics and Gynaecology Service, Douala General Hospital, Douala, Cameroon.

Received: 3 March 2021 Accepted: 12 April 2021

Published online: 23 April 2021

\section{References}

1. Say L, Chou D, Gemmill A, Tunçalp Ö, Moller A-B, Daniels J, et al. Global causes of maternal death: a WHO systematic analysis. Lancet Glob Health. 2014;2(6):e323-33. https://doi.org/10.1016/S2214-109X(14)70227-X.

2. The DHS Program - Cameroon: Standard DHS, 2018 [Internet]. [cited 28 Oct 2020]. Available from: https://dhsprogram.com/what-we-do/survey/surveydisplay-511.cfm.

3. Tebeu P-M, Halle-Ekane G, Da Itambi M, Mbu RE, Mawamba Y, Fomulu JN Maternal mortality in Cameroon: a university teaching hospital report. Pan Afr Med J. 2015;21. Accessed 30 Dec 2019.

4. Van den Akker T, Brobbel C, Dekkers OM, Bloemenkamp KW. Prevalence, indications, risk indicators, and outcomes of emergency peripartum hysterectomy worldwide: a systematic review and meta-analysis. Obstet Gynecol. 2016;128(6):1281-94. https://doi.org/10.1097/AOG.0000000000001 736 PMID: 27824773

5. Nwobodo E, Nnadi D. Emergency obstetric hysterectomy in a tertiary Hospital in Sokoto, Nigeria. Ann Med Health Sci Res. 2012;2(1):37-40. https://doi.org/10.4103/2141-9248.96935.

6. Tebeu PM, Ndive PE, Ako WT, Biyaga PTT, Fomulu JN, Doh AS. Emergency obstetric hysterectomy at University Hospital, Yaoundé Cameroon. Int J Gynaecol Obstet Off Organ Int Fed Gynaecol Obstet. 2013;120(1):91-2.

7. Daskalakis G, Anastasakis E, Papantoniou N, Mesogitis S, Theodora M, Antsaklis A. Emergency obstetric hysterectomy. Acta Obstet Gynecol Scand. 2007:86(2):223-7. https://doi.org/10.1080/00016340601088448.

8. Chauhan BR, Patel AJ. Complications of emergency obstetric hysterectomy in Gujarat, India. Int J Reprod Contracept Obstet Gynecol. 2017;6(11):4950. https://doi.org/10.18203/2320-1770.ijrcog20175006.

9. De la Cruz CZ, Thompson EL, O'Rourke K, Nembhard WN. Cesarean section and the risk of emergency peripartum hysterectomy in high-income countries: a systematic review. Arch Gynecol Obstet. 2015;292(6):1201-15. https://doi.org/10.1007/s00404-015-3790-2 Epub 2015 Jun 24. PMID: 26104125.

10. Demirci O, Tuğrul AS, Yilmaz E, Tosun Ö, Demirci E, Eren YS. Emergency peripartum hysterectomy in a tertiary obstetric center: nine years evaluation. J Obstet Gynaecol Res. 2011 37(8):1054-60. https://doi.org/10.1111/j.14470756.2010.01484.x.

11. Cassella C. The World Health Organisation has called for a reduction in Csections. ScienceAlert. Available from: https://www.sciencealert.com/whoglobal-caesarean-rates-double-15-years. Accessed 1 Dec 2019.

12. Nana Njamen $T$, Tchente Nguefack C, Nkwabong E, Metogo Mbengono JA, Verla V, Kenfack G, Halle Ekane G, Njamen Nana C, Kouam Siegning L, Belley Priso E, Ngowe Ngowe M. Emergency peripartum hysterectomy at a tertiary care Hospital in Douala, Cameroon. Afr J Integr Health. 2017;7:14-8.

13. Baskett TF. Emergency obstetric hysterectomy. J Obstet Gynaecol J Inst Obstet Gynaecol. 2003;23(4):353-5. https://doi.org/10.1080/0144361031 000119466.

14. Forna F, Miles AM, Jamieson DJ. Emergency peripartum hysterectomy: a comparison of cesarean and postpartum hysterectomy. Am J Obstet Gynecol. 2004;190(5):1440-4. https://doi.org/10.1016/j.ajog.2004.02.021.

15. Rossi A, Lee R, Chmait R. Emergency postpartum hysterectomy for uncontrolled postpartum bleeding: a systematic review reply. Obstet Gynecol. 2010;115:637-44. https://doi.org/10.1097/AOG.0b013e3181cfc007.

16. Lee DHY. Peripartum hysterectomy: comparison of the outcome of caesarean and postpartum hysterectomy. 2016.

17. Soper DE, Mayhall CG, Dalton HP. Risk factors for intraamniotic infection: a prospective epidemiologic study. Am J Obstet Gynecol. 1989;161(3):562-6; discussion 566-8.

18. Dare FO, Bako AU, Ezechi OC. Puerperal sepsis: a preventable post-partum complication. Trop Doct. 1996;28(121):96. 1-4 1. Available from: https://www. ncbi.nlm.nih.gov/pubmed/9594677. Accessed 20 Nov 2018.
19. AlBuhairan B, Hind D, Hutchinson A. Antibiotic prophylaxis for wound infections in total joint arthroplasty: a systematic review. J Bone Joint Surg Br. 2008;90(7):915-9.

20. Salkind AR, Rao KC. Antibiotic prophylaxis to prevent surgical site infections. Am Fam Physician. 2011;83(5):585-90.

21. Katiuska Miliani, François L'Hériteau, Pascal Astagneau, Non-compliance with recommendations for the practice of antibiotic prophylaxis and risk of surgical site infection: results of a multilevel analysis from the INCISO Surveillance Network. J Antimicrob Chemother. 2009;64(6):1307-15.

\section{Publisher's Note}

Springer Nature remains neutral with regard to jurisdictional claims in published maps and institutional affiliations.
Ready to submit your research? Choose BMC and benefit from:

- fast, convenient online submission

- thorough peer review by experienced researchers in your field

- rapid publication on acceptance

- support for research data, including large and complex data types

- gold Open Access which fosters wider collaboration and increased citations

- maximum visibility for your research: over $100 \mathrm{M}$ website views per year

At $\mathrm{BMC}$, research is always in progress.

Learn more biomedcentral.com/submissions 